\title{
O reitor Hesio Cordeiro (1992-1995)
}

| ${ }^{1}$ Roberto José Ávila Cavalcanti Bezerra |

\author{
1 Universidade do Estado do Rio de Janeiro. Rio de Janeiro-RJ, Brasil (avilabezerra@gmail.com). ORCID: 0000-0002-5435-6606 \\ Recebido em: 02/06/2021 \\ Aprovado em: 03/08/2021 \\ Revisado em: 23/08/2021
}

DOI: http://dx.doi.org/10.1590/S0103-73312021310308

A chegada à Reitoria da UERJ, em 1992, tem uma história de longa caminhada iniciada em 1984, no primeiro processo de eleição direta para reitor em uma Universidade brasileira. Em 1984, apesar de eleito em primeiro lugar, Hesio não foi indicado para o cargo pelo governador na época, que escolheu o segundo colocado. Esse mesmo governador, em 1992, após vitória de Hesio em eleição direta, o nomeou reitor da UERJ (UERJ, 1996).

Ele iniciou o mandato com a ambiciosa meta de mudar o perfil da UERJ em quatro anos, principalmente no que tange à formação de um importante centro de produção do conhecimento, baseado na pesquisa e desenvolvimento tecnológico com forte influência na formação de alunos, funcionários e professores. Assumiu também compromisso com a discussão nacional sobre autonomia universitária e implementou um forte programa de descentralização e avaliação do desempenho da universidade.

Em nível nacional, no que tange à autonomia, a UERJ passou a ter forte participação nos principais fóruns de debate, como CRUB (Conselho de Reitores das Universidades Brasileiras), ABRUEM (Associação Brasileira de Universidades Estaduais e Municipais) e no MEC. 
No estado, encaminhou e teve sucesso na implantação, junto à ALERJ, da Lei n. 2.208/1993, delegando ao reitor autorização para modificar os orçamentos nas fontes 10 e 16, dando maior agilidade na execução orçamentária de contratos e convênios que viriam a contribuir para maior captação de recursos externos e maior eficiência nos processos de administração financeira da universidade.

Criou o SIDES (Sistema de Desembolso Descentralizado), que proporcionou às unidades e departamentos a aquisição de material de consumo necessário diariamente, permitindo maior rapidez nesse processo que, seria ampliado mais adiante para a compra de material permanente e realização de pequenas obras e serviços de manutenção.

Ainda em 1993, adotou medidas descentralizadoras, com a criação do Sistema Integrado de Informaçóes Contábeis (SIC), permitindo às sub-reitorias e outros órgãos terem, pela primeira vez, a definição de seus custos reais, incentivando a constituição de programas, laboratórios e núcleos de caráter interdisciplinar, dotados de autonomia relativa, ágeis na captação de recursos, incentivando maior integração de ensino (graduação e pós-graduação), pesquisa e extensão.

A Comissão Permanente de Carga Horária e Avaliação Docente (COPAD) passou a inserir seus relatórios na rede da Diretoria de Informática, permitindo a qualquer pessoa com conta no sistema, acesso a esses dados, democratizando a informação.

Destaco aqui as principais realizaçôes da UERJ durante os quatro anos em que Hesio foi reitor:

- Maior vestibular isolado, com 53 mil candidatos.

- Participação em inúmeras comissóes, grupos de trabalho e projetos relacionados ao desenvolvimento do Estado do Rio de Janeiro, em que podemos incluir a participação na Rede Rio de Tecnologia, a criação do Campus Regional de Resende e Nova Friburgo, criação do Centro de Estudos Ambientais na Vila Dois Rios na Ilha Grande, programa de promoção e defesa da cidadania e inúmeras ações culturais.

- Ampliação dos recursos das fontes 10 e 16 para um total de $26 \%$ do orçamento executado.

- Projetos com a União Europeia (Alfa, Santos Dumont e Margaret Mee).

- Investimentos totais de 1992 a 1995, tomando por base o dólar médio de cada ano: US\$27,4 milhóes. 
- Aumento do número de projetos submetidos e aprovados na Fundaçáo Banco do Brasil, FAPERJ, FINEP, CNPq e maior soma de auxílios da Capes.

- Reestruturação das licenciaturas.

- Revisão da estrutura curricular de diversos cursos de graduação.

- Aumento e flexibilização de cursos eletivos, passando de 112 para 806, e de 607 alunos para 2.301.

- Consolidação e aprovação de normas para a graduação.

- Aumento de bolsas-auxílio para estudantes de 500 para 1.910, incluindo um programa de bolsas de Iniciação Cientifica para alunos da graduação e IC Júnior para alunos do CAP UERJ.

- Estágio externo reformulado, envolvendo convênios com 708 empresas.

- Criação de novos cursos de mestrado e doutorado, com aumento de $60 \%$ do número de alunos.

- Mudança no perfil de titulação de professores, passando de 33\% para 37\% com título de mestrado e de 14,5\% para 19\% com doutorado.

- Aprovação e implantação do Prociência, programa em regime de dedicação exclusiva para docentes, com acompanhamento e avaliação periódica dos mesmos, renovada ou não ao final de cada três anos, sendo selecionados 100 pesquisadores para o primeiro ano do programa (com previsão de 200 vagas para o ano de 1996), os quais passam a receber uma bolsa no valor de 70\% do salário-base de cada um.

- Funcionamento pleno do Teatro Noel Rosa, com o incremento das realizações de oficinas culturais.

- Recuperação e conclusão do Teatro Odylo Costa Filho, com investimentos do orçamento UERJ (fonte 00), do estado, através da Secretaria de Cultura e do Ministério da Cultura.

- Criação da Editora da UERJ (EdUERJ), com cerca de 35 títulos publicados entre 1994-95.

- Criaçáo da UNATI (Universidade Aberta da $3^{a}$ Idade), com cerca de dois mil usuários por ano.

- Ampliação e implantaçáo dos campi de Duque de Caxias, São Gonçalo, Nova Friburgo, Ilha Grande, Resende e Araruama.

- Elaboração de projeto técnico para construção de nova instalação do Colégio de Aplicação (CAP) em um novo terreno. 
- Ampliação do Escritório Modelo da Faculdade de Direito e aprovação na instalação do Tribunal de Pequenas Causas no $10^{\circ}$ andar do campus Maracaná.

- Pleno funcionamento do HUPE e assinatura de convênio de cogestão com o Ministério da Saúde referente ao PAM-São Francisco Xavier, para estágios e prestação de serviços à comunidade.

- Internato no interior do estado.

- Criação e estruturação da Superintendência de Recursos Humanos.

- Revisão dos enquadramentos do plano de cargos e salários, beneficiando 2.500 servidores.

- Aumento no número de cursos para atualização e educação continuada de 21 para 130, beneficiando 4.710 funcionários.

- Criação do InvestUERJ para ensino supletivo.

- Realização de concursos públicos, incorporando mil funcionários novos para suprir vagas decorrentes de aposentadorias nos últimos oito anos.

- Abertura e realização de concursos para 66 vagas de professor titular, já existentes há cerca de 20 anos.

- Definição e execução de uma nova política salarial, de forma a manter o poder aquisitivo dos salários de todos os profissionais da UERJ.

- Acordos coletivos com a representaçâo do pessoal docente e técnico-administrativo com cláusulas qualitativas e quantitativas justas.

- Ampliação do acervo e informatização do Sistema de Bibliotecas e da Superintendência de Recursos Humanos (SRH).

- Estruturação da Diretoria de Informática.

- Assinatura de convênios com a IBM e Microsoft.

- Ampliação da plataforma de microcomputadores de cerca de 50 para 900.

- Instalação e desenvolvimento do NET/UERJ, ligando a Internet via Rede Rio.

- Aquisição de equipamentos para os laboratórios por meio de fontes 00 e 10, num total de US\$ 6.544.898,00, incluindo um moderno e primeiro microscópio eletrônico da UERJ.

- Implantação de nova central eletrônica de telefonia para toda a UERJ.

- Realização de obras em toda a UERJ, para melhoria do acesso para portadores de deficiência.

- Criação do DESSAÚDE na SRH, com espaço exclusivo para atendimento de funcionários do campus e do HUPE, com média de 1.560 atendimentos/mês. 
Uma Universidade não pode se caracterizar como uma instituição elitista, que ignora a realidade da maioria da população do Estado e do País. A partir dessa convicção, a administração desenvolveu uma ampla política de integração com a comunidade, levando também seus serviços e conhecimentos a vários municípios do interior do Estado do Rio de Janeiro. Ampliou ainda os programas comunitários de extensão, se consolidando como espaço de encontro entre as culturas popular e erudita.

Hesio Cordeiro (UERJ, 1996).

\section{Referência}

UNIVERSIDADE DO ESTADO DO RIO DE JANEIRO. UERJ a caminho da Excelência (1992-1995). Relatório de final de gestão. Rio de Janeiro: UERJ, 1996. 